\title{
The Application of Novel Electrochemical Approach to Antioxidant Activity Assay of Metal Porphyrins with Bulky 3,5-Diisobornyl-4-hydroxyphenyl Moieties
}

\author{
Tatyana Rocheva1, Vladimir Tyurin², Dmitrii Belykh¹, Anna Moiseeva², Jingwei Zhang2, \\ Evgeny Buravlev1, Irina Chukicheva1, Alexander Kutchin'1, Elena Milaeva2,3* \\ ${ }^{1}$ Institute of Chemistry, Komi Scientific Center, Ural Branch, Russian Academy of Sciences, Syktyvkar, Russia \\ ${ }^{2}$ Department of Medicinal Chemistry and Fine Organic Synthesis, Lomonosov Moscow State University, \\ Moscow, Russia \\ ${ }^{3}$ Institute of Physiologically Active Compounds of Russian Academy of Sciences, Chernogolovka, Moscow \\ Region, Russia \\ Email: milaeva@org.chem.msu.ru
}

Received 27 August 2014; revised 12 October 2014; accepted 27 October 2014

Copyright (C) 2014 by authors and Scientific Research Publishing Inc.

This work is licensed under the Creative Commons Attribution International License (CC BY).

http://creativecommons.org/licenses/by/4.0/

(c) (i)

\section{Abstract}

The complexes of biogenic metals $\left(\mathrm{Zn}^{2+}, \mathrm{Cu}^{2+}, \mathrm{Co}^{2+}, \mathrm{Mn}^{3+}, \mathrm{Fe}^{3+}\right)$ based on meso-tetra(3,5-diisobornyl-4-hydroxyphenyl)porphyrin 1 were synthesized. The electrochemical behavior of these compounds was studied using cyclic voltammetry (CV) and rotating disk electrode (RDE) techniques. The antioxidant activity of complexes was estimated by means of the electrochemical assay based on the hydrogen atom transfer reaction to the stable radical 2,2'-diphenyl-1-picrylhydrazyl (DPPH). The RDE method was applied for this process monitoring. It was shown that the efficiency of the metal complexes $\left(\mathrm{Cu}^{2+}, \mathrm{Co}^{2+}, \mathrm{Mn}^{2+}, \mathrm{Ni}^{2+}, \mathrm{Fe}^{3+}\right)$ is practically the same order as that of free base porphyrin 1 . However the $\mathrm{Zn}^{2+}$ complex demonstrates significantly higher antioxidant activity, and the stoichiometry of the reaction was determined as $\sigma=4$. The results demonstrate that porphyrin macrocycle can directly affect the antioxidant properties of 2,6-diisobornylphenol.

\section{Keywords}

Metal Porphyrins, Cyclic Voltammetry, Rotating Disk Electrode, 2,2'-Diphenyl-1-picrylhydrazyl,

\footnotetext{
*Corresponding author.
}

How to cite this paper: Rocheva, T., Tyurin, V., Belykh, D., Moiseeva, A., Zhang, J.W., Buravlev, E., Chukicheva, I., Kutchin, A. and Milaeva, E. (2014) The Application of Novel Electrochemical Approach to Antioxidant Activity Assay of Metal Porphyrins with Bulky 3,5-Diisobornyl-4-hydroxyphenyl Moieties. American Journal of Analytical Chemistry, 5, 1028-1036.

http://dx.doi.org/10.4236/ajac.2014.515109 


\section{Antioxidant Activity}

\section{Introduction}

The oxidative stress caused by an excessive generation of reactive oxygen species (ROS) such as superoxide radical-anion $\mathrm{O}_{2}^{--}$, hydroxyl radical $\mathrm{HO}^{*}$, peroxy radicals $\mathrm{LOO}^{*}$, lipid hydroperoxides $\mathrm{LOOH}$ leads to cardiovascular diseases, mutagenic changes, cancerous tumor growth and ageing of living organisms on the whole. A number of methods and variations have been developed and applied for the measurement of antioxidant capacity and efficiency, but very often there is lack of correlation between activities determined on the same material by different assays and between activities determined by the same assay in different laboratories. Therefore, the search for novel effective antioxidants, as well as for methods to assess the antioxidant activity, is a topical task [1]-[3]. Among the classes of well-known natural antioxidants vitamins E, ascorbic acid, glutathione, and so forth, $\alpha$-tocopherol and its synthetic analogues, sterically hindered phenols, are of particular importance [4]. The substituted 2,6-dialkylphenols are widely used as inhibitors of free radicals formation in the oxidative destruction of natural and synthetic substrates. The mechanism of their physiological action is associated with the stable phenoxyl radicals formation in the process of hydrogen atom abstraction by highly reactive LOO $^{\circ}$ radicals [5].

The synthesis and study of polytopic compounds possessing several pharmacophore centers in the molecule are of a particular interest, because such a combination is able not only to enhance the well-known physiological activity but also to cause the appearance of new types of physiological activity [6] [7]. Butylated hydroxytoluene (BHT, 2,6-di-tert-butyl-4-methylphenol) is a known synthetic antioxidant used in the manufacture of foodstuffs. 2,6-Diisobornyl-4-methylphenol is currently undergoing preclinical trials as a promising drug [8]. Previously, it has been shown that tetra(3,5-di-tert-butyl-4-hydroxyphenyl)porphyrin, containing BHT moieties, and its analogue with the palmitoyl residues exhibit a high antioxidant activity in the model oxidation reaction of (Z)-9octadecenoic acid, as well as in the lipids peroxidation processes in Wistar rat liver homogenates [9] [10]. The activity of tetra(3,5-diisobornyl-4-hydroxyphenyl)porphyrin $\mathbf{1}$ was studied by electrochemical methods and it was shown that this compound may be considered either as a promising antioxidant [11], or as a membrane protector [12]. The introduction of the metal in the porphyrin core can have a direct effect on the antioxidant properties due to the participation in redox processes, which is of interest in terms of search for novel antioxidants.

In this work, starting from compound 1, metal porphyrins M-1 were synthesized (Scheme 1) and their antioxidant properties were studied using an electrochemical DPPH test [13]-[15].

\section{Materials and Methods}

IR spectra of a diffuse reflectance were recorded FTIR Shimadzu IR Prestige $21 \mathrm{in} \mathrm{KBr}$. Electronic spectra (UVVis) were obtained on Shimadzu UV-1700 spectrometer using quartz cuvettes $10 \mathrm{~mm}$ thickness (chloroform as sample of comparison). ${ }^{1} \mathrm{H}$ NMR spectrum of the complex Zn-1 was recorded on a Bruker Avance II spectrometer (operating frequency $300 \mathrm{MHz}$ ) in a substance solution in $\mathrm{CDCl}_{3}$. MALDI mass spectra were recorded on a Bruker Ultraflex TOF/TOF (matrix-dihydroxybenzoic acid). Monitoring of the reaction proceeding was performed using TLC plates "Sorbfil". Column chromatography was performed sequentially on $\mathrm{Al}_{2} \mathrm{O}_{3}$ (40/200 micron, grade "pure") and further on $\mathrm{SiO}_{2}$ (60/200 micron, Alfa Aesar), eluent-chloroform. Compound $\mathbf{1}$ was synthesized from meso-diastereomers of 2,6-diisobornyl-4-methylphenol as previously described [16].

Zn-Tetrakis $\{3-\{(1 R, 2 S, 4 S)-(1,7,7-t r i m e t h y l b i c y c l o[2.2 .1]$ hept-2-yl)-5-\{(1S,2R,4R)-(1,7,7-trimethylbicyclo[2.2.1] hept-2-yl\}-4-hydroxyphenyl\}porphyrin, Zn-1. A solution of porphyrin 1 (0.2 g, $0.113 \mathrm{mmol})$ in $21 \mathrm{~mL}$ of chloroform was added to a solution of zinc acetate $(0.6 \mathrm{~g}, 3.28 \mathrm{mmol})$ in $10 \mathrm{~mL}$ of methanol. The reaction mixture was stirred vigorously at room temperature for $40 \mathrm{~min}$, then washed with water and the product was purified by column chromatography. It was obtained $0.09 \mathrm{~g}$ (43\%) of Zn-1 complex as a purple fine crystalline powder which upon trituration electrified. IR spectrum, $v, \mathrm{~cm}^{-1}$ : 3603 (OH), $3120(\mathrm{CH}), 2951,2875,1456,1371,1338$ (Me, $\left.\mathrm{CH}_{2}\right), 1600,1523$ (C=C), 1631, 796, 713 (benzene ring). UV-Vis $\left(\mathrm{CHCl}_{3} ; \lambda\right.$, nm): 594.5, 553.0, 472.5, $429.5 \mathrm{~m} / \mathrm{z}$ (MALDI): for $[\mathrm{MH}]^{+}\left(\mathrm{C}_{124} \mathrm{H}_{15} \mathrm{~N}_{4} \mathrm{O}_{4} \mathrm{Zn}\right)$ calculated: 1830.15 , found: $1830.46 .{ }^{1} \mathrm{H}$ NMR $\delta_{\mathrm{H}}$ ppm: 0.90 $\left(24 \mathrm{H}\right.$, br s, $\left.\mathrm{C}^{10,10^{\prime}} \mathrm{H}_{3}\right), 0.98\left(24 \mathrm{H}, \mathrm{s}, \mathrm{C}^{9,9^{\prime}} \mathrm{H}_{3}\right), 1.15\left(24 \mathrm{H}, \mathrm{s}, \mathrm{C}^{8,8^{\prime}} \mathrm{H}_{3}\right), 1.37-2.11\left(48 \mathrm{H}, \mathrm{m}, \mathrm{C}^{3,3^{\prime}, 4,4^{\prime}}, \mathrm{C}^{5,5^{\prime}} \mathrm{H}_{2}\right.$, 


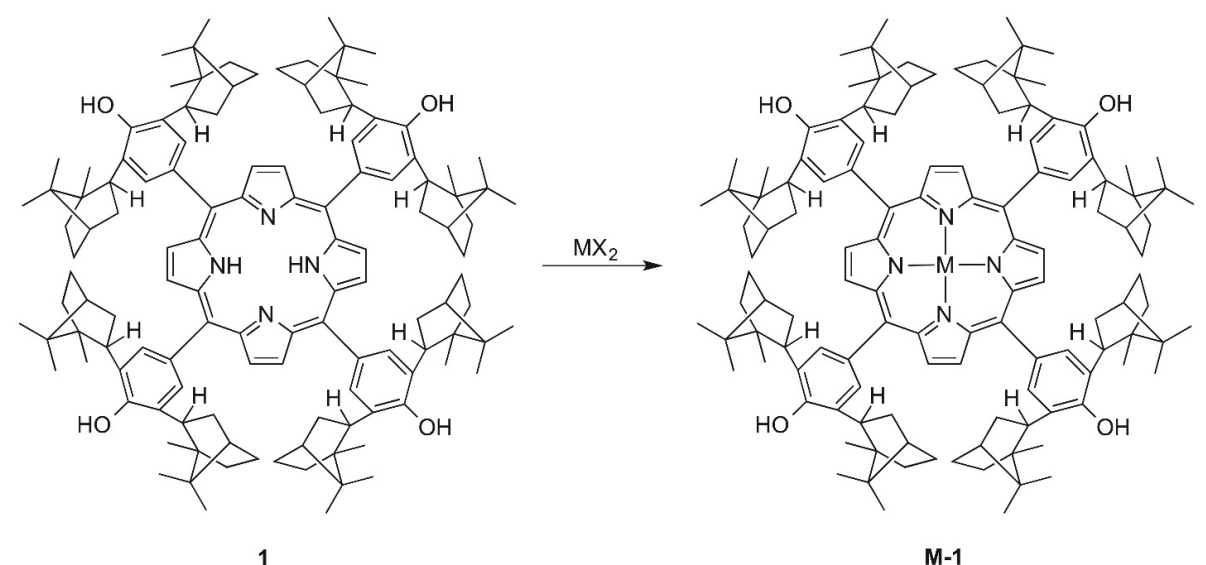

Zn-1: $\mathrm{MX}_{2}=\mathrm{Zn}(\mathrm{OAc})_{2}, \mathrm{CHCl}_{3} ; \mathbf{C u}-\mathbf{1}: \mathrm{MX}_{2}=\mathrm{Cu}(\mathrm{OAc})_{2} ; \mathbf{C o - 1}: \mathrm{MX}_{2}=\mathrm{Co}(\mathrm{OAc})_{2} ; \mathbf{F e}(\mathbf{O H})-\mathbf{1}: \mathrm{M}=\mathrm{FeOH}$.

Scheme 1. Synthesis of metal porphyrins.

$\left.\mathrm{C}^{6,6^{\prime}} \mathrm{H}_{2}\right), 2.22-2.48\left(8 \mathrm{H}, \mathrm{m}, \mathrm{H}^{3,3^{\prime}}\right), 3.39\left(8 \mathrm{H}, \mathrm{br} \mathrm{m}, \mathrm{H}^{2,2^{\prime}}, \mathrm{J} \approx 8.0 \mathrm{~Hz}\right), 5.23(4 \mathrm{H}, \mathrm{s}, \mathrm{OH}), 8.06\left(8 \mathrm{H}, \mathrm{s}, \mathrm{H}^{14,16}\right)$, $8.96\left(8 \mathrm{H}, \mathrm{s} \mathrm{H}^{\beta}\right)$.

Cu-Tetrakis $\{3-\{(1 R, 2 S, 4 S)-(1,7,7-t$ trimethylbicyclo[2.2.1]hept-2-yl)-5-\{(1S,2R,4R)-(1,7,7-trimethylbicyclo [2.2.1] hept-2-yl)\}-4-hydroxyphenyl \}porphyrin, Cu-1. A solution of porphyrin $\mathbf{1}(0.1 \mathrm{~g}, 0.057 \mathrm{mmol})$ in $10 \mathrm{~mL}$ of chloroform was added to a solution of copper acetate $(0.3 \mathrm{~g}, 1.65 \mathrm{mmol})$ in $7 \mathrm{~mL}$ of methanol. The reaction mixture was stirred vigorously at room temperature for $20 \mathrm{~min}$, then washed with water and the product was purified by column chromatography. It was obtained $0.057 \mathrm{~g}$ (55\%) of $\mathbf{C u}-\mathbf{1}$ complex as a purple fine crystalline powder which upon trituration electrified. IR spectrum, $v, \mathrm{~cm}^{-1}$ : $3603(\mathrm{OH}), 3118(\mathrm{CH}), 2951,2875,1458,1371$, $1342\left(\mathrm{Me}, \mathrm{CH}_{2}\right), 1602,1533(\mathrm{C}=\mathrm{C}), 1631,796,713$ (benzene ring). UV-Vis $\left(\mathrm{CHCl}_{3} ; \lambda, \mathrm{nm}\right)$ : 583.5, 544.0, 479.5, $425 \mathrm{~m} / \mathrm{z}$ (MALDI): for $[\mathrm{MH}]^{+}\left(\mathrm{C}_{124} \mathrm{H}_{157} \mathrm{~N}_{4} \mathrm{O}_{4} \mathrm{Cu}\right)$ calculated: 1829.15, found: 1829.57 .

Co-Tetrakis $\{3-\{(1 R, 2 S, 4 S)-(1,7,7-t r i m e t h y l b i c y c l o[2.2 .1]$ hept-2-yl)-5-\{(1S,2R,4R)-(1,7,7-trimethylbicyclo[2.2.1] hept-2-yl)\}-4-hydroxyphenyl \}porphyrin, Co-1. To a solution of porphyrin $1(0.1 \mathrm{~g}, 0.057 \mathrm{mmol})$ in $25 \mathrm{~mL}$ of toluene was added cobalt acetate $(0.3 \mathrm{~g}, 1.69 \mathrm{mmol})$ and $0.5 \mathrm{~mL}$ acetylacetone was poured. The mixture was refluxed for $20 \mathrm{~min}$. After the reaction, the reaction mixture in toluene was applied to the column and the product was isolated by column chromatography. It was obtained $0.060 \mathrm{~g}(58 \%)$ Co-1 complex as a dark red fine crystalline powder. IR spectrum, $v, \mathrm{~cm}^{-1}$ : $3603(\mathrm{OH}), 3105(\mathrm{CH}), 2951,2875,1446,1369,1348\left(\mathrm{Me}, \mathrm{CH}_{2}\right), 1544$ $(\mathrm{C}=\mathrm{C}), 1618,796,711$ (benzene ring). UV-Vis $\left(\mathrm{CHCl}_{3} ; \lambda, \mathrm{nm}\right): 533.0,419.0 \mathrm{~m} / \mathrm{z}$ (MALDI): for $[\mathrm{MH}]^{+}$ $\left(\mathrm{C}_{124} \mathrm{H}_{157} \mathrm{~N}_{4} \mathrm{O}_{4} \mathrm{Co}\right)$ calculated: 1825.15, found: 1825.41 .

$\mathrm{Mn}(\mathrm{OH})$-Tetrakis $\{3-\{(1 R, 2 S, 4 S)-(1,7,7-t r i m e t h y l b i c y c l o[2.2 .1]$ hept-2-yl)-5-\{(1S,2R,4R)-(1,7,7-trimethylbicyc lo[2.2.1]hept-2-yl)\}-4-hydroxyphenyl\}porphyrin, $\mathbf{M n}(\mathbf{O H})-\mathbf{1}$. A solution of porphyrin $\mathbf{1}(0.1 \mathrm{~g}, 0.057 \mathrm{mmol})$ and manganese(II) chloride tetrahydrate $(0.3 \mathrm{~g}, 1.5 \mathrm{mmol})$ in $20 \mathrm{~mL}$ of dimethylformamide (DMF) was refluxed for $10 \mathrm{~min}$, then poured into water and the precipitate was filtered, washed with water, dried on air. The product was isolated by column chromatography. It was obtained $0.060 \mathrm{~g}(58 \%)$ of the $\mathbf{M n}(\mathbf{O H})-\mathbf{1}$ complex in the form of fine crystalline purple powder which upon trituration electrified. IR spectrum, $v, \mathrm{~cm}^{-1}$ : $3603(\mathrm{OH}), 3111(\mathrm{CH})$, 2949, 2875, 1456, 1371, $1338\left(\mathrm{CH}_{3}, \mathrm{CH}_{2}\right), 1627,1597$ (C=C), 1670, 800, 711 (benzene ring). UV-Vis $\left(\mathrm{CHCl}_{3} ; \lambda\right.$, $\mathrm{nm}): 682,5482.5 \mathrm{~m} / \mathrm{z}$ (MALDI): for $[\mathrm{MH}]^{+}\left(\mathrm{C}_{124} \mathrm{H}_{159} \mathrm{~N}_{4} \mathrm{O}_{5} \mathrm{Mn}\right)$ calculated: 1821.16, found: 1821.51.

$\mathrm{Fe}(\mathrm{OH})$-Tetrakis $\{3-\{(1 R, 2 S, 4 S)-(1,7,7-t r i m e t h y l b i c y c l o[2.2 .1]$ hept-2-yl)-5-\{(1S,2R,4R)-(1,7,7-trimethylbicyclo [2.2.1]hept-2-yl)\}-4-hydroxyphenyl $\}$ porphyrin, $\mathbf{F e}(\mathbf{O H})-\mathbf{1}$. To a solution of porphyrin $\mathbf{1}$ (0.1 g, $0.057 \mathrm{mmol})$ in $20 \mathrm{~mL}$ of DMF was added iron(II) bromide $(0.3 \mathrm{~g}, 1.39 \mathrm{mmol})$. The reaction mixture was refluxed for $10 \mathrm{~min}$, then poured into water and the precipitate was filtered, washed with water, dried on air. The product was isolated by column chromatography. It was obtained $0.050 \mathrm{~g}$ (48\%) of the complex $\mathbf{F e}(\mathbf{O H})-\mathbf{1}$ in the form of fine crystalline purple powder which upon trituration electrified. IR spectrum, $v, \mathrm{~cm}^{-1}: 3603(\mathrm{OH}), 3118(\mathrm{CH}), 2951,2875$, 1456, 1371, 1336 (Me, $\left.\mathrm{CH}_{2}\right), 1597(\mathrm{C}=\mathrm{C}), 1658,800,715$ (benzene ring). UV-Vis $\left(\mathrm{CHCl}_{3} ; \lambda, \mathrm{nm}\right): 512.0,429.5$ $\mathrm{m} / \mathrm{z}$ (MALDI): for $[\mathrm{M}]^{+}\left(\mathrm{C}_{124} \mathrm{H}_{158} \mathrm{~N}_{4} \mathrm{O}_{5} \mathrm{Fe}\right)$ calculated: 1838.15 , found: 1837.56 .

Electrochemical measurements were carried out in DMF in a three-electrode cell under an argon atmosphere. The CV and polarization curves were obtained by using the potentiostat "IPC-pro" ("Volta", Russia) connected 
to a computer. DMF was purified prior to use by standard methods [17]. Working electrode-stationary or rotating platinum, gold or glassy carbon (GC) electrode of $3 \mathrm{~mm}$ diameter, a platinum plate was used as the auxiliary electrode. Background electrolyte $-5 \times 10^{-4} \mathrm{M} \mathrm{Bu}_{4} \mathrm{NClO}_{4}$ (99\%, “Acros”). Rotation speed of the electrode was $2800 \mathrm{rev} / \mathrm{min}$. The $(\mathrm{Ag}|\mathrm{AgCl}| \mathrm{KCl})$ with a waterproof diaphragm was used as a reference electrode. DPPH concentration was $50 \mu \mathrm{M}$, the measurements were done during the period of time from 1 to 5 hours. In the case of $\mathbf{Z n - 1}$ complex, when determining reaction stoichiometry, the ratio of the concentrations $[\mathrm{DPPH}]:[\mathrm{compound}]=5: 1$ was used.

\section{Results and Discussion}

The synthesis of metal porphyrins (M-1) was carried out by the reaction of free base porphyrin $\mathbf{1}$ with metal salts (Scheme 1). Complexes of $\mathrm{Zn}$, Cu are relatively easily formed by the action of metal acetates and compound $\mathbf{1}$ in chloroform and methanol mixture at room temperature. Compound Co-1 was obtained by refluxing the starting porphyrin $\mathbf{1}$ with the cobalt acetate and acetylacetone in toluene. Complexes $\mathbf{F e}(\mathbf{O H})-\mathbf{1}$, and $\mathbf{M n}(\mathbf{O H})-\mathbf{1}$ were obtained by refluxing the compound $\mathbf{1}$, respectively, with iron(II) bromide and manganese(II) chloride in DMF. During this procedure the intermediate iron(II) and manganese(II) porphyrins undergo the oxidation by molecular oxygen to form complexes $\mathbf{F e}(\mathbf{O H})-\mathbf{1}$ and $\mathbf{M n}(\mathbf{O H})-\mathbf{1}$ respectively. The structure of the M-1 complexes was determined on the basis of mass spectrometry (MALDI), UV-Vis and IR spectroscopy; for diamagnetic complex Zn-1 ${ }^{1} \mathrm{H}-\mathrm{NMR}$ spectroscopy was used. The bands number in the UV-Vis spectra of the compounds M-1 decreases comparing with the spectrum of the ligand 1, that corresponds to the introduction of the metal into the porphyrin macrocycle. In the mass spectra the peaks corresponding to their molecular ions, protonated molecular ions and ion peaks resulting from cleavage of the hydrogen atoms of one or two phenolic hydroxyl groups are observed. It should be mentioned that for $\mathrm{Co}^{2+}, \mathrm{Mn}^{3+}, \mathrm{Fe}^{3+}$ the changes of the oxidation state during the implementation in the coordination sphere of the porphyrin are possible. In the case of iron and manganese complexes ions $m / z$ values which correspond to $\mathbf{F e}(\mathbf{O H})-\mathbf{1}$ and $\mathbf{M n}(\mathbf{O H})-\mathbf{1}$ complexes with hydroxyl anion as extra-ligand are observed in the mass spectra. The ion value $\mathrm{m} / \mathrm{z}$ which attributes to Co-1 without extraligand, corresponding to the Co oxidation state $(+2)$, is recorded in the mass spectrum. The absence of the signal in the negative (approximately $-2.7 \mathrm{ppm}$ ) field that corresponds to $\mathrm{NH}$ groups protons of the porphyrin macrocycle as well as the $\beta$-protons signals shift towards the strong field in the ${ }^{1} \mathrm{H}$-NMR spectrum of the complex Zn-1 comparing to the porphyrin $\mathbf{1}$. The signals of other peripheral substituents in the porphyrin macrocycle do not change. Despite the fact that the paramagnetism of the other complexes does not allow to use the ${ }^{1} \mathrm{H}-\mathrm{NMR}$ spectroscopy for the their structures study, the immutability of peripheral substituents is established by IR spectroscopy: a band at $3603 \mathrm{~cm} \cdot v^{-1}$ that corresponds to the stretching vibrations of the phenolic hydroxyl group, the most active reaction center in the molecule, is observed in the spectra of all the complexes $\mathbf{M - 1}$ as well as in the spectrum of the starting free base porphyrin. Oscillations corresponding to groups of other fragments also remain virtually unchanged and completely analogous to those of the original ligand $\mathbf{1}$ and zinc complex, the immutability of the peripheral substituents in the macrocycle is confirmed by ${ }^{1} \mathrm{H}-\mathrm{NMR}$ spectroscopy. The absence of stretching vibrations band of NH bonds in the macrocycle $\left(v 3318 \mathrm{~cm}^{-1}\right)$ which was observed in the spectrum of the ligand $\mathbf{1}$ is a characteristic feature of the obtained porphyrines IR spectra. We can conclude that the mass spectrometry data, IR and electron spectroscopy can reliably determine the structure of the paramagnetic porphyrines $\mathbf{C u}-1, \mathbf{C o - 1}, \mathbf{F e}(\mathbf{O H})-1$, and $\mathbf{M n}(\mathbf{O H})-1$. Thus, in this paper a series of complexes with transition metal cations $\left(\mathrm{Zn}^{2+}, \mathrm{Cu}^{2+}, \mathrm{Co}^{2+}, \mathrm{Fe}^{3+}, \mathrm{Mn}^{3+}\right.$ ) based on meso-tetrakis(3,5-diisobornyl-4-hydroxyphenyl) porphyrin $\mathbf{1}$ is synthesized.

Antioxidant activity (AA) of the free base porphyrin $\mathbf{1}$ has been previously studied by using electrochemical DPPH test, which is based on the hydrogen atom transfer reaction to stable radical 2,2-diphenyl-1-picrylhydrazyl (DPPH) (Scheme 2(a)). It has been shown that AA is significantly higher than the that of the antioxidant 2,6-diisobornyl-4-methylphenol even at a concentration ratio [porphyrin]:[2,6-diisobornyl-4-methylphenol] = $1: 4$, that points out that the porphyrin macrocycle influences upon the antioxidant activity mechanism. The electrochemical approach to estimate AA is based on the fact that the DPPH radical exhibits two reversible oneelectron transitions in the range of $0.2-0.8 \mathrm{~V}(\mathrm{Ag}|\mathrm{AgCl}| \mathrm{Kl})$, that corresponds to oxidation and reduction of the radical respectively (Scheme 2(b)) [18] [19]. This fact allows us to monitor the reaction of DPPH with an antioxidant by the drop of the peak current value (CV method), or by the decrease of the limiting diffusion current Id polarization curve (RDE method) [14] [15]. 

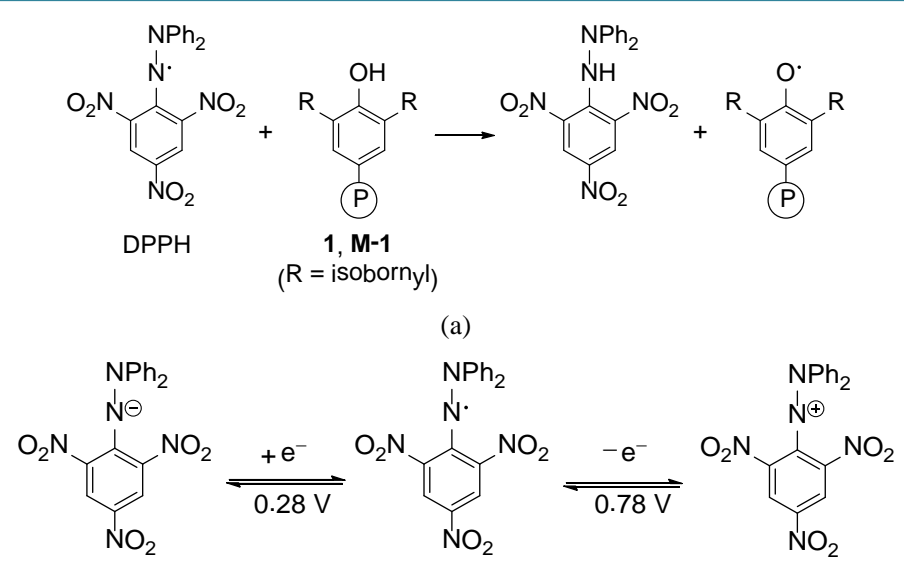

(b)

Scheme 2. Mechanism of DPPH reaction with phenolic antioxidants (a); Redox transitions of DPPH (b).

In this work, the RDE technique was applied, which provides greater accuracy due to uniform mixing and equalization of concentrations in the whole volume of the solution. From the Levich equation [20], for fixed values and the electrode area and rotation velocity, the ratio of the current at the beginning of the reaction (no additives) and at given moment of time is determined by the DPPH concentration ratio:

$$
I / I_{0}=C / C_{0} \text {, }
$$

where $I_{0}$ is the diffusion limiting current of polarization curve at the initial DPPH concentration $C_{0}, I$ is the current at a DPPH concentration $C$ at a given moment of time. Thus, we can easily obtain the kinetic curves of concentration change from the electrochemical data. The well known spectrophotometrical DPPH-test [21] [22] cannot be applied in this case, since the compounds under study are coloured ones, and one of the absorption bands of porphyrins ( $\lambda_{\max }$ for $\mathbf{1}$ is $522.5 \mathrm{~nm}$ ) are close to the absorption band of DPPH (517 nm). It should also be noted that in a number of recent papers it was pointed out that the use of spectrophotometric test leads to a divergence of activity data obtained in different groups even in the case of known antioxidants (BHT, trolox, $\alpha$-tocopherol), thus, this method requires further validation [23] [24].

In order to determine whether an electrochemical DPPH test may be applied to the antioxidant activity assay in this case the redox behavior of metal porphyrins has been studied by CV. The measurements were carried out in DMF at different electrodes (glassycarbon (GC), $\mathrm{Au}, \mathrm{Pt}$ ) on a background of $n-\mathrm{Bu}_{4} \mathrm{NClO}_{4}$. The oxidation and reduction of complexes takes place in several stages, wherein there is no overlap of the peak of DPPH reduction with the peaks of metal porphyrins redox transitions (Table 1). Investigation of the electrochemical behavior of the complexes presents certain difficulties due to their limited solubility and the inability to get quality voltammograms of all the complexes at one electrode. In this regard, the peak potentials listed in Table 1 were obtained at different electrodes.

The voltammograms of porphyrin $\mathbf{1}$ display two irreversible one-electron oxidation peaks in the anodic range (Figure 1). The first peak is apparently due to the oxidation of the porphyrin ring to the radical cation, followed by its rapid reduction via intramolecular electron transfer (IET) from the phenol group (Scheme 3). The irreversible character of the peak is caused by the rapid chemical stage of proton elimination (the EC mechanism). The second peak corresponds to one-electron oxidation of the phenoxyl radical thus formed to the corresponding cation [25]. The oxidation peaks of phenol groups are not observed because of the shift to the discharge region of the supporting electrolyte molecules. In the cathodic range porphyrin $\mathbf{1}$ reduction proceeds in one-electron step to form a stable radical anion. The degree of the reversibility on a Pt electrode is higher than that on GC (Figure 1(b)). On the other hand, oxidation and reduction of all the complexes proceed irreversibly according to ECE mechanism.

The reduction of Mn-1 and Fe-1 complexes takes place at lower cathode potential values, that allows one to suggest that the initial reduction step is the metal reduction $[\mathrm{Fe}(\mathrm{III}) \rightarrow \mathrm{Fe}(\mathrm{II})]$. The reduction of porphyrins Zn-1, Cu-1, and Co-1 proceed on the ligand moiety in the same way as of free base $\mathbf{1}$ (Figure 2, Scheme 2).

The study of antioxidant activity of metal porphyrins was also completed in DMF at an initial concentration 
Table 1. Electrochemical potentials (Ag|AgCl|KCl (aq., sat.)) and the antioxidant efficiences (AOE) values of compounds under study (DMF, $0.1 \mathrm{M} n-\mathrm{Bu}_{4} \mathrm{NClO}_{4}, \mathrm{C}=5 \times$ $10^{-4} \mathrm{M}$, time of reaction with DPPH $5 \mathrm{~h}$ ).

\begin{tabular}{ccccc}
\hline Compound & Electrode & $\mathbf{E}^{\text {Red }}, \mathbf{V}$ & $\mathbf{E}^{\mathbf{O x}}, \mathbf{V}$ & $\mathbf{A O E}, \mathbf{\%}$ \\
\hline $\mathbf{1}$ & GC & $-1.15 ;-1.58$ & $0.86 ; 1.21 ; 1.46$ & $\mathbf{6 5 . 3 8}$ \\
$\mathbf{\text { Co-1 }}$ & GC & $-0.91 /-0.76 ;-2.14$ & $1.03 ; 1.35$ & $\mathbf{6 6 . 2 6}$ \\
$\mathbf{M n}-\mathbf{1}$ & Au (heating) & $-0.54 ;-1.39 ;-1.79$ & $1.00 ; 1.32 ; 1.46$ & $\mathbf{3 0 . 1 5}$ \\
Fe-1 & Au & $-0.58 ;-0.87 ;-1.79 ;-1.98$ & $0.35 ; 0.97 ; 1.17$ & $\mathbf{6 4 . 8 5}$ \\
Cu-1 & GC & $-1.25 /-1.20 ;-1.89 /-1.78$ & 0.99 & $\mathbf{6 7 . 4 7}$ \\
Zn-1 & GC & $-1.43 ;-1.99$ & $0.74 ; 0.94$ & $\mathbf{8 3 . 9 1}$ \\
\hline
\end{tabular}

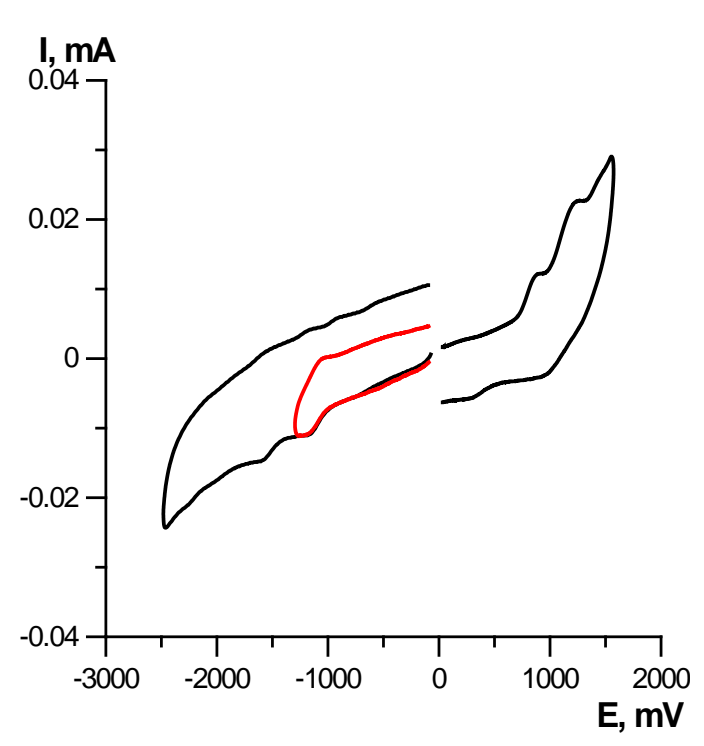

(a)

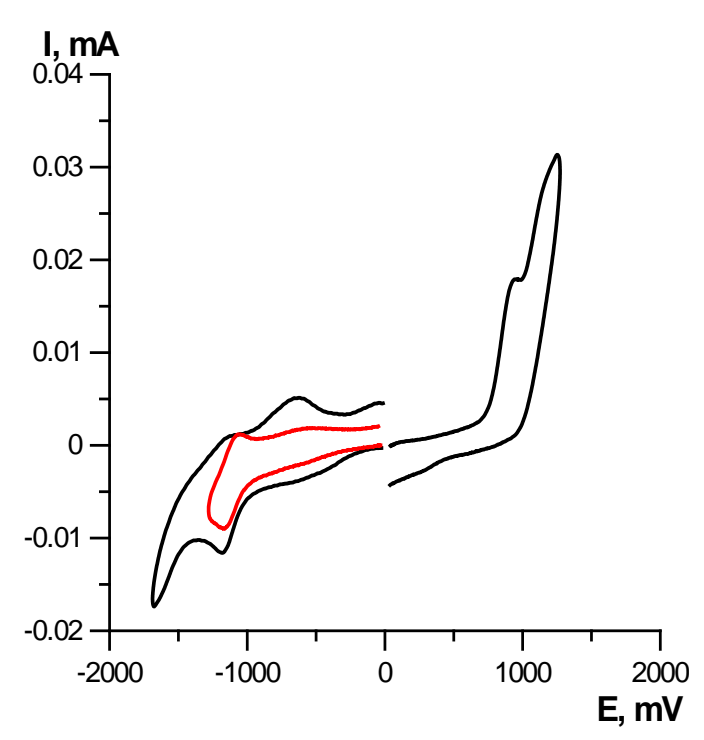

(b)

Figure 1. CV curves of porphyrin 1 on GC 1 (a) and Pt (b) electrodes in DMF (scan rate $200 \mathrm{mV} / \mathrm{s}, \mathrm{C}=10^{-3} \mathrm{M}$, $0.5 \times 10^{-3} n-\mathrm{Bu}_{4} \mathrm{NClO}_{4}, \mathrm{Ag}|\mathrm{AgCl}| \mathrm{KCl}$ (sat.)).

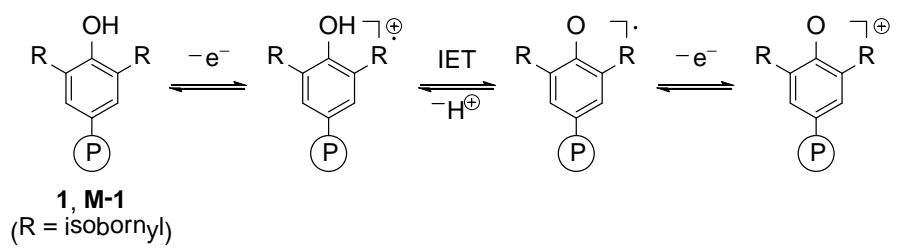

Scheme 3. Suggested mechanism of porphyrin 1 and complexes Zn-1, Cu-1, and Co-1 oxidation.

ratio [DPPH]:[compound] = 1:1 (DPPH concentration $\left.5 \times 10^{-4} \mathrm{M}\right)$. The concentrations were chosen in order to provide a comparatively short period of the reaction time (up to $5 \mathrm{~h}$ ). Kinetic curves of DPPH concentration change during period of time 20 min obtained from the polarization curves according Equation (1) are presented in Figure 3.

It can be seen that the maximum reaction rate is observed in the initial period of reaction. In order to assess the activity quantitatively the parameter AOE numerically equal to the percentage of reacted in the reaction of DPPH was used:

$$
\mathrm{AOE}=\left(1-C_{\text {fin }} / C_{0}\right) \times 100(\%),
$$




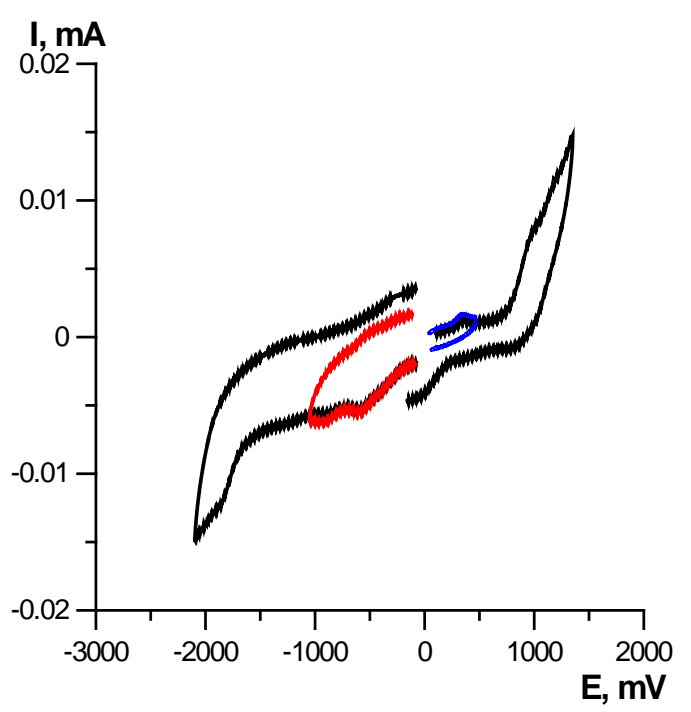

(a)

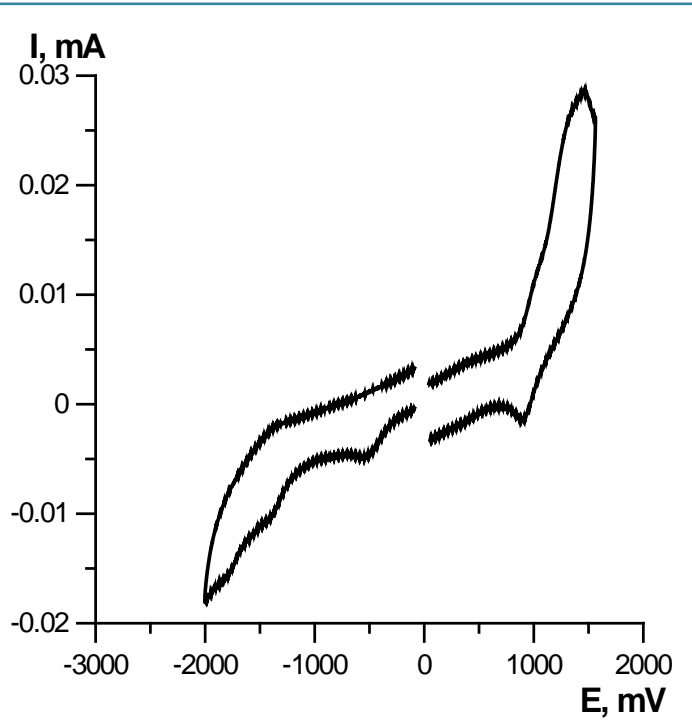

(b)

Figure 2. CV curves of complexes Fe-1 (a) and Mn-1 (b) in DMF on Au-electrode (scan speed of $200 \mathrm{mV} / \mathrm{s}, \mathrm{C}=$ $10^{-3} \mathrm{M}, 0.5 \times 10^{-3}, n-\mathrm{Bu}_{4} \mathrm{NClO}_{4}, \mathrm{Ag}|\mathrm{AgCl}| \mathrm{KCl}$ (sat.)).

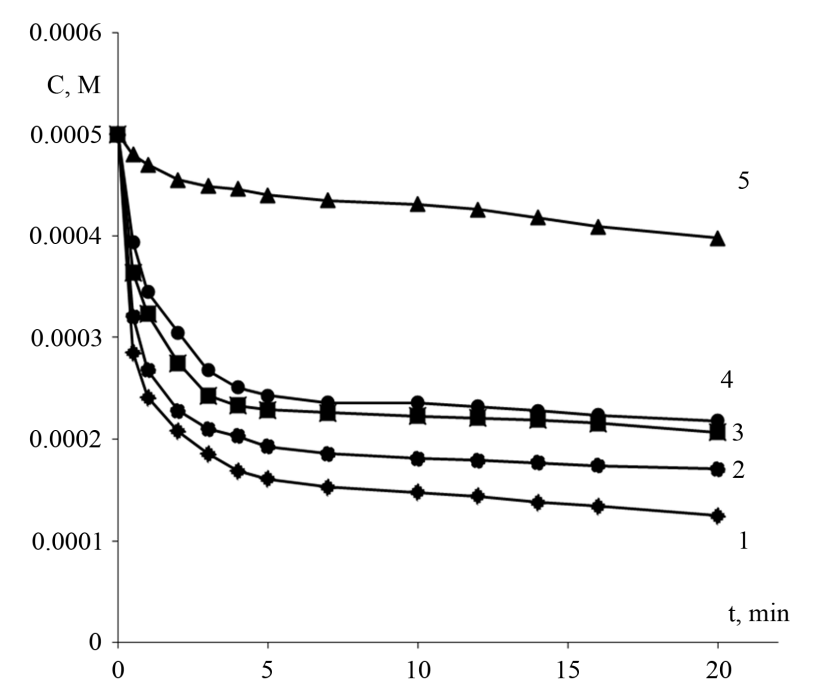

Figure 3. Kinetic curves of DPPH concentration change obtained with RDE in the presence of metal porphyrins: 1: Zn-1, 2: Co-1, 3: Cu-1, 4: Fe-1, 5: Mn-1 (C = $5 \times 10^{-4} \mathrm{~mol} / \mathrm{L} n-\mathrm{Bu}_{4} \mathrm{NClO}_{4}, \mathrm{DPPH}$ concentration $0.5 \mathrm{mM}$, the ratio [DPPH]:[compound] $=1: 1)$.

where $C_{0}$-initial concentration of DPPH, $C_{\text {fin }}$ - final concentration corresponding to the time the kinetic curve receive the plateau.

AOE values of metal porphyrins under study are listed in Table 1. It can be seen from these data that activity of Fe-1, Co-1 is practically the same as that of the free base porphyrin 1. Thus, in this case, the introduction of metal ion into the core of porphyrin macrocycle does not alter significantly the antioxidant properties. The activity of the Mn-1 was lower (30.15\%). On the other hand, the complex Zn-1 exhibits greater activity than the porphyrin 1 (AOE $=83.9 \%$ ). This compound is a leader in a series of compounds studied and can be considered as the most promising antioxidant. The activity of complexes increases in a row:

$$
\text { Mn-1 }<\text { Fe-1 } \approx \text { Co-1 }<\text { Cu-1 }<\text { Zn-1 . }
$$

A more detailed study of the compound $\mathbf{Z n - 1}$ and DPPH reaction makes possible to determine the stoichi- 
ometry of this process equal to $\sigma=4$. Thus, these data suggest the participation of each of phenolic substituent in the reaction with DPPH. As it has been shown previously in the case of porphyrins, containing 2,6-di-tertbutylphenol substituents, Zn-complex also exhibits the highest activity [15]. We suggest that the higher activity in this case is associated with a change in the redox properties of the molecule: the overlap of the metal ion free $d$-orbitals with a porphyrin macrocycle orbitals results in a shift of oxidation potentials to the cathodic range (Table 1). In general it can be concluded that the introduction of the metal ion in the macrocycle of porphyrins, has a significant influence on the antioxidant activity of porphyrins containing bulky alkyl substituents. It is noteworthy that, in accordance with the data [11], all of the complexes studied exhibit markedly higher activity than 2,6-diisobornyl-4-methylphenol and belong to a class of effective antioxidants.

\section{Conclusion}

The complexes of biogenic metals $\left(\mathrm{Zn}^{2+}, \mathrm{Cu}^{2+}, \mathrm{Co}^{2+}, \mathrm{Mn}^{3+}, \mathrm{Fe}^{3+}\right.$ ) based on meso-tetrakis(3,5-diisobornyl-4-hydroxyphenyl)porphyrin were synthesized and their redox properties were studied. The antioxidant activity of complexes was estimated using the electrochemical approach (DPPH-test). It was demonstrated that antioxidant properties of these compounds depend on the metal nature. All compounds demonstrate activity higher than that of a known antioxidant 2,6-di-tert-butyl-4-methylphenol (BHT) and 2,6-diisobornyl-4-methylphenol, and thus they can be considered as effective antioxidants. The study completely demonstrates that redox and antioxidant properties are tightly connected.

\section{Acknowledgements}

This work was supported by RFBR (12-03-00937a, 13-03-12460 ofi_m2) and the Ural Branch of the Russian Academy of Sciences (competition of scientific projects of young scientists and graduate students RAS, project 14-3-NP-3).

\section{References}

[1] Migliore, L. and Coppedè, F. (2009) Environmental-Induced Oxidative Stress in Neurodegenerative Disorders and Aging. Mutation Research, 674, 73-84. http://dx.doi.org/10.1016/j.mrgentox.2008.09.013

[2] Liu, Z.-Q. (2010) Chemical Methods to Evaluate Antioxidant Ability. Chemical Reviews, 110, 5675-5691. http://dx.doi.org/10.1021/cr900302x

[3] Niki, E. (2010) Assessment of Antioxidant Capacity in Vitro and in Vivo. Free Radical Biology and Medicine, 49, 503-515. http://dx.doi.org/10.1016/j.freeradbiomed.2010.04.016

[4] Denisov, E.T. (1995) Handbook of Antioxidants: Bond Dissociation Energies, Rate Constants, Activation Energies, and Enthalpies of Reactions. CRC Press, Boca Raton, 174 p.

[5] Niki, E., Yoshida, Y., Saito, Y. and Noguchi, N. (2005) Lipid Peroxidation: Mechanisms, Inhibition, and Biological Effects. Biochemical and Biophysical Research Communications, 338, 668-676. http://dx.doi.org/10.1016/j.bbrc.2005.08.072

[6] Buravlev, E.V., Chukicheva, I.Yu., Belykh, D.V. and Kuchin, A.V (2007) Simple Synthesis of a Terpenophenol-Chlorin Conjugate with an Amide Bond. Chemistry of Natural Compounds, 43, 678-681. http://dx.doi.org/10.1007/s10600-007-0226-7

[7] Milaeva, E.R. (2011) Metal-Based Antioxidants-Potential Therapeutic Candidates for Prevention the Oxidative StressRelated Carcinogenesis: Mini-Review. Current Topics in Medicinal Chemistry, 11, 2703-2713. http://dx.doi.org/10.2174/156802611798040741

[8] Plotnikov, M.B., Chernysheva, G.A., Smol’yakova, V.I., Ivanov, I.S., Kuchin, A.V., Chukicheva, I.Iu. and Krasnov, E.A. (2009) Neuroprotective Effects of Dibornol and Mechanism of Its Action in Rats with Cerebral Ischemia. Vestnik Rossiǔskŏ Akademii Meditsinskikh Nauk, 11, 12-17. (In Russian)

[9] Milaeva, E., Shpakovsky, D., Gracheva, Yu., Gerasimova, O., Tyurin, V. and Petrosyan, V. (2003) Oleic Acid Peroxidation in the Presence of Metallo-Porphyrins. Journal of Porphyrins and Phthalocyanines, 7, 719-724. http://dx.doi.org/10.1142/S1088424603000896

[10] Milaeva, E.R., Gerasimova, O.A., Jingwei, Z., Shpakovsky, D.B., Syrbu, S.A., Semeykin, A.S., Koifman, O.I., Kireeva, E.G., Shevtsova, E.F., Bachurin, S.O. and Zefirov, N.S. (2008) Synthesis and Antioxidative Activity of Metalloporphyrins Bearing 2,6-Di-tert-butylphenol pendants. Journal of Inorganic Biochemistry, 102, 1348-1358. http://dx.doi.org/10.1016/j.jinorgbio.2008.01.022 
[11] Tyurin, V.Y., Zhang, J., Moiseeva, A.A., Milaeva, E.R., Belykh, D.V., Buravlev, E.V., Rocheva, T.K., Chukicheva, I.Y. and Kuchin, A.V. (2013) Comparative Study of Redox Characteristics and Antioxidant Activity of Porphyrins with 2,6-Dialkylphenol Groups. Doklady Chemistry, 450, 152-155. http://dx.doi.org/10.1134/S0012500813060025

[12] Rocheva, T.K., Belykh, D.V., Buravlev, E.V., Chukicheva, I.Y., Shevchenko, O.G. and Kutchin, A.V. (2013) Book of Abstracts of the 1st Conference on Medical Chemistry "MedChem Russia-2013”. Moscow, 252. (In Russian)

[13] Tyurin, V.Y., Meleshonkova, N.N., Dolganov, A.V., Glukhova, A.P. and Milaeva, E.R. (2011) Electrochemical Method in Determination of Antioxidative Activity Using Ferrocene Derivatives as Examples. Russian Chemical Bulletin, 60, 647-655.

[14] Tyurin, V.Y., Wu, Y., Dolganov, A.V. and Milaeva, E.R. (2011) Antioxidant Activity Assay of 2,6-Di-tert-butylphenols with Phosphonate Groups Using Cyclic Voltammetry. Doklady Chemistry, 436, 31-33. http://dx.doi.org/10.1134/S0012500811020042

[15] Tyurin, V.Y., Zhang, J., Glukhova, A. and Milaeva, E.R. (2011) Electrochemical Antioxidative Activity Assay of Metalloporphyrins Bearing 2,6-Di-tert-butylphenol Groups Based on Electrochemical DPPH-Test. Macroheterocycles, 4, 211-212. http://dx.doi.org/10.6060/mhc2011.3.10

[16] Belykh, D.V., Rocheva, T.K., Buravlev, E.V., Chukicheva, I.Y. and Kutchin, A.V. (2012) The First Tetra(mesoaryl)porphyrin with Isobornyl Substituents. Macroheterocycles, 5, 121-124. http://dx.doi.org/10.6060/mhc2012.120572b

[17] Gordon, A.J. and Ford, R.A. (1973) The Chemist’s Companion: A Handbook of Practical Data, Techniques and References. John Wiley and Sons, Inc., New York, 560 p.

[18] Solon, E. and Bard, A.J. (1964) The Electrochemistry of Diphenylpicrylhydrazyl. Journal of the American Chemical Society, 86, 1926-1928. http://dx.doi.org/10.1021/ja01064a005

[19] Solon, E. and Bard, A.J. (1964) Coulometric Study of the Reaction of Diphenylpicrylhydrazyl and Bromide Ion. Journal of Physical Chemistry, 68, 1144-1147. http://dx.doi.org/10.1021/j100787a030

[20] Galus, Z. (1971) Teoretyczne podstawy elektroanalizy chemicznej: Polarografia, chronowoltamperometria, chronopotencjometria, metoda wirującego dysku. Państwowe Wydawnictwo Naukowe, Warszawa, 390 p.

[21] Brand-Williams, W., Cuvelier, M.E. and Berset, C. (1995) Use of a Free Radical Method to Evaluate Antioxidant Activity. LWT, Food Science and Technology, 28, 25-30.

[22] Bondet, V., Brand-Williams, W. and Berset, C. (1997) Kinetics and Mechanisms of Antioxidant Activity Using the DPPH Free Radical Method. LWT, Food Science and Technology, 30, 609-615.

[23] Mishra, K., Ojha, H. and Chaudhury, N.K. (2012) Estimation of Antiradical Properties of Antioxidants Using DPPH Assay: A Critical Review and Results. Food Chemistry, 130, 1036-1043. http://dx.doi.org/10.1016/j.foodchem.2011.07.127

[24] Sharma, O.P. and Bhat, T.K. (2009) DPPH Antioxidant Assay Revisited. Food Chemistry, 113, 1202-1205. http://dx.doi.org/10.1016/j.foodchem.2008.08.008

[25] Meleshonkova, N.N., Shpakovsky, D.B., Fionov, A.V., Dolganov, A.V., Magdesieva, T.V. and Milaeva, E.R. (2007) Synthesis and Redox Properties of Novel Ferrocenes with Redox Active 2,6-Di-tert-butylphenol Fragments: The First Example of 2,6-Di-tert-butylphenoxyl Radicals in Ferrocene System. Journal of Organometallic Chemistry, 692, 53395344. http://dx.doi.org/10.1016/j.jorganchem.2007.08.013

\section{Abbreviations}

BHT: butylated hydroxytoluene(2,6-di-tert-butyl-4-methylphenol);

DPPH: 1,1-diphenyl-2-picrylhydrazyl( $\alpha, \alpha$-diphenyl- $\beta$-picrylhydrazyl);

LP: lipid peroxidation;

$\mathrm{CV}$ : cyclic voltammetry;

RDE: rotating disk electrode;

GC: glassycarbon electrode;

AA: antioxidant activity;

AOE: antioxidant efficiency;

DMF: dimethylformamide. 
Scientific Research Publishing (SCIRP) is one of the largest Open Access journal publishers. It is currently publishing more than 200 open access, online, peer-reviewed journals covering a wide range of academic disciplines. SCIRP serves the worldwide academic communities and contributes to the progress and application of science with its publication.

Other selected journals from SCIRP are listed as below. Submit your manuscript to us via either submit@scirp.org or Online Submission Portal.
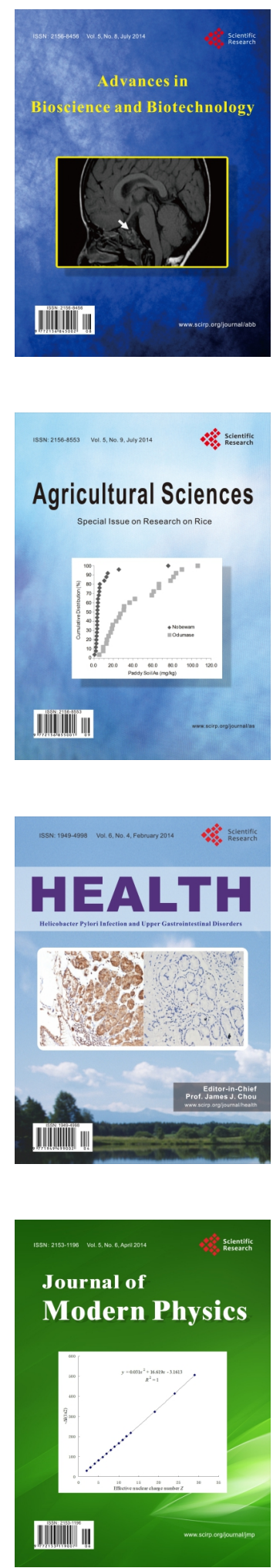
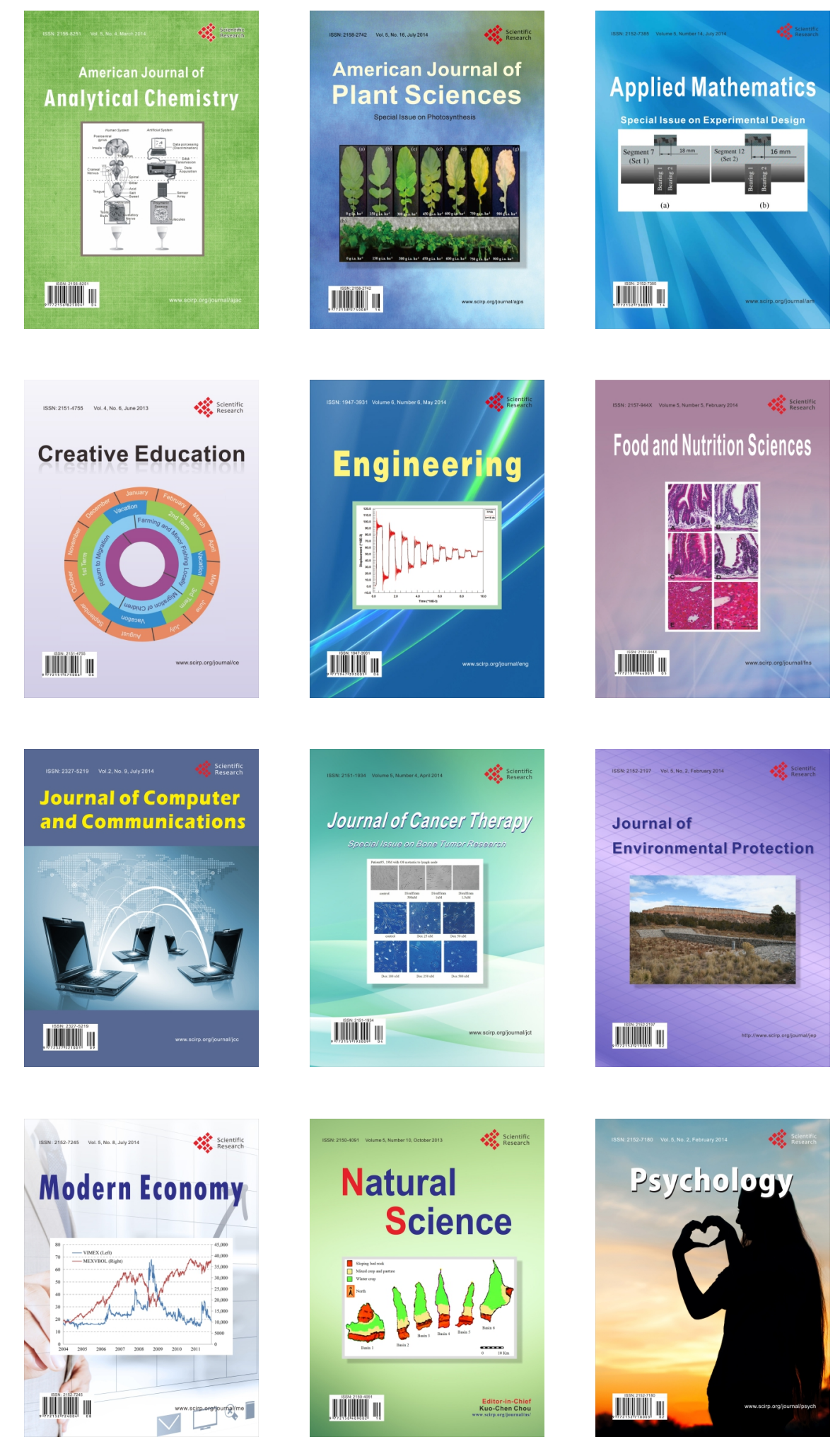